\title{
Patients' Anxiety Related to Dental Radiographic Examinations: Levels, Perception and Management
}

\author{
Ansiedad de los Pacientes Relacionada con los Exámenes \\ Radiográficos Dentales: Niveles, Percepción y Manejo
}

\begin{abstract}
Eliana Dantas Costa1; Luciano Augusto Cano Martins'; Samuel Carvalho Chaves-Junior²; Emerson Tavares Sousa; Maria Beatriz Duarte Gavião²; Rosana de Fátima Possobon ${ }^{3}$ \& Matheus Lima Oliveira ${ }^{1}$
\end{abstract}

COSTA, E. D.; MARTINS, L. A. C.; CHAVES-JUNIOR, S. C.; SOUSA, E. T.; GAVIÃO, M. B. D.; POSSOBON, R. F. \& OLIVEIRA, M. L. Ansiedad de los pacientes relacionada con los exámenes radiográficos dentales: niveles, percepción y manejo. Int. J. Odontostomat., 15(4):971-979, 2021.

\begin{abstract}
This study evaluated patients' anxiety levels related to dental radiographic examinations in addition to dentists' perception and management. Salivary alpha-amylase (SAA) activity of 47 patients was measured before and after exposure to radiographic examinations to assess their anxiety level and compared using Wilcoxon test. Mann-Whitney test assessed the sAA activity related to sex, type of examination, and previous experience with radiographic examinations. 50 dentists were interviewed using a semi-structured script containing open-ended questions perception on their patients' anxiety. Before the radiographic examination, sAA activity was significantly higher for women $(p \leq 0.05)$. SAA activity significantly increased after the examination for men, patients of both sexes with no previous experience and for those who underwent CBCT $(p \leq 0.05)$. Anxiety was reported to be observed in adult patients' speech and pediatric patients' behavior. Dental radiographic examinations may be a source of anxiety for women before the examination. After the examination, men, patients with no previous experience, and those subjected to CBCT present higher anxiety levels. Dentists perceive anxiety in adult and pediatric patients differently.
\end{abstract}

KEY WORDS: anxiety, alpha -amylases, radiology, dentistry, patient care.

\section{INTRODUCTION}

Anxiety is a physiological response commonly observed in patients undergoing dental treatment due to the lack of previous experience and the procedurerelated pain (Astramskaite et al., 2016; Yıldızer Keris, 2017; Yıldırım et al., 2018). Although dental radiology does not make use of potentially anxiogenic objects and instruments, such as needles for local anesthesia, burs, and dental handpieces (Doebling \& Rowe, 2000; Oosterink et al., 2008) anxiety should not be underestimated because, unlike other dental specialties, patients are exposed to ionizing radiation (Doebling \& Rowe). Additionally, the robustness of the radiological equipment, e.g. panoramic radiography and cone beam computed tomography (CBCT), may scare patients and increase their level of anxiety (SpinNeto \& Wenzel, 2016; Yıldızer Keris).

The detection of anxiety can be accomplished through questionnaires and specific biological markers. Questionnaires detect and track anxiety levels (Said et al., 2013; Karibe et al., 2014; Yıldızer Keris), and their reliability depend on the self-perception and sincerity of the applicants. More objectively, the physiological investigation of anxiety can be estimated by the activity of alpha-amylase, which is an enzyme released in higher amount after the sympatheticadrenomedullary axis activation under stressful situations (Rohleder \& Nater, 2009). This biological

\footnotetext{
${ }^{1}$ Division of Oral Radiology, Department of Oral Diagnosis, Piracicaba Dental School, University of Campinas. Piracicaba, São Paulo, Brazil.

${ }^{2}$ Department of Pediatric Dentistry, Piracicaba Dental School, University of Campinas, Piracicaba, Brazil.

${ }^{3}$ Department of Social Dentistry, Piracicaba Dental School, University of Campinas, Piracicaba, São Paulo, Brazil.
}

Received: 2021-05-13 Accepted: 2021-07-15 
marker is very sensitive and can be non-invasively obtained from the patient's saliva (Said et al.; Karibe et al.; Rohleder \& Nater). Previous studies have confirmed the applicability of alpha-amylase for the detection of dental anxiety (Furlan et al., 2012; Karibe et al.; Salas Huamani et al., 2019).

Due to the indication of the radiographic examination in the most diverse dental specialties, it is essential that professionals and dentistry students understand the patients' experience during these examinations, aiming to avoid the need for repetitions, in addition to offering minimally traumatic treatment. However, this is a considerable challenge in daily routine because some patients have difficulty in expressing themselves clearly. Then, the biomarker alpha amylase can help professionals in such task and potentially lead to better patient management. Thus, the aim of this study was to verify patients' anxiety levels related to dental radiographic examinations in addition to dentists' perception and management.

\section{MATERIAL AND METHOD}

This study was approved by the local ethics committee (CAAE: 91084418.2 .0000 .5418$)$, and all the participants signed an informed consent form.

\section{Patient anxiety assessment}

Sample selection and characterization. Forty-seven patients older than 18 years of age and undergoing panoramic radiography or CBCT using the OP300 Maxio unit (Instrumentarium Imaging, Tuusula, Finland) were randomly selected from an oral radiology clinic.

Table I. Characterization of the patients included in this study.

\begin{tabular}{llc}
\hline & \multicolumn{1}{c}{ Variable } & $\mathrm{N}$ \\
\hline Sex [n(\%)] & Female & $36(76.6 \%)$ \\
& Male & $11(23.4 \%)$ \\
Age [years (SD)] & & $34(17.4)$ \\
& & \\
& Panoramic radiography & $37(78.7 \%)$ \\
Examination indication & Cone-beam computed tomography & $10(21.3 \%)$ \\
& & \\
& General evaluation & $24(51.1 \%)$ \\
& Tooth extraction planning & $21(44.7 \%)$ \\
& Bony lesion evaluation & $2(4.2 \%)$ \\
& & \\
& Yes & $27(57.4 \%)$ \\
& No & $20(42.5 \%)$ \\
\hline
\end{tabular}

Exclusion criteria considered patients with potential alterations in alpha-amylase levels due to the following variables: fasting less than 1 hour, coffee and alcoholic beverages intake, physical exercise one hour before the radiographic examination, and smokers with xerostomia or under beta-blockers treatment (Said et al.; Rohleder \& Nater). Patients with systemic diseases that affect movement, such as Parkinson's disease, were also excluded.

Out of the total selected sample of patients, 76.6 $\%$ of them were female, $78.7 \%$ underwent panoramic radiography, $51.1 \%$ had the exam prescribed for overall evaluation of the jaws, and $57.4 \%$ had previous experience with radiographic examination. The mean age was of 34 years old (standard deviation of 17.4 years) (Table I).

The sample size of patients was calculated based on a study that assessed anxiety levels through alpha-amylase activity in dentistry (Sadi et al.) with a power test higher than $80 \%$, error type I and significance level of $5 \%$.

Saliva collection. Saliva was collected twice from the selected patients ten minutes before and ten minutes after the radiographic examinations using a cotton swab and a plastic tube (Salivette, Sarstedt, Germany). The swab was placed under the patient's tongue to get entirely imbibed with saliva for about 2 minutes, and the collected material was centrifuged at $16097.2 \mathrm{~g} \mathrm{(3000}$ rpm for 15 minutes). The debris was discarded and the supernatant was kept at $-80 \circ \mathrm{C}$ for the analysis (Furlan et al.). The collection procedures were done only in the afternoon between 2-4 pm to avoid variation of the circadian rhythm (Rohleder \& Nater).

Alpha-amylase dosage. The collected saliva was assayed for alpha-amylase activity using an immunoassay kit (ELISA) according to the manufacturer's instructions (Salimetrics, Carlsbad, CA, USA). The enzymatic kinetics of alphaamylase was measured by spectrophotometry at absorbance of $405 \mathrm{~nm}$ at $37^{\circ} \mathrm{C}$ (Eon, BioTek Instruments, Winooski, VT, USA) (Furlan et al.; Salas Huamani et al.), and expressed as international units per milliliter of saliva $(\mathrm{U} / \mathrm{mL})$ 
COSTA, E. D.; MARTINS, L. A. C.; CHAVES-JUNIOR, S. C.; SOUSA, E. T.; GAVIÃO, M. B. D.; POSSOBON, R. F. \& OLIVEIRA, M. L. Ansiedad de los pacientes relacionada con los exámenes radiográficos dentales: niveles, percepción y manejo. Int. J. Odontostomat., 15(4):971-979, 2021.

(Rohleder \& Nater; Furlan et al.; Salas Huamani et al.). As proposed by Bradford (1976), the total protein concentration in saliva normalized the alpha-amylase activity (Furlan et al.) using the Bradford reagent (Sigma Aldrich, Saint Louis, MO, USA) and bovine serum albumin (Sigma-Aldrich, Jurubatuba-SP, Brasil) as standard, with concentrations of $0.5,0.25,0.125$ and $0.06 \mathrm{mg} / \mathrm{mL}$ and the values were converted to $\mathrm{U} / \mathrm{mg}$ of total protein.

Patient interview. After the radiographic examination and the final saliva collection, sex and examination indication were collected. The patients were interviewed to evaluate the anxiety level by the time the examination was scheduled and during the procedure itself, and the occurrence of physical manifestations of anxiety, such as muscle tension, restlessness, sweating, increased respiratory and heart rate (Yıldızer Keris; Furlan et al.; Salas Huamani et al.), through a previously tested form. The interview questions, as detailed in Table II in the results section, were elaborated by experienced professors of psychology and oral radiology, who followed the yes/ no format, along with "does not apply".

Statistical analysis. The Wilcoxon test compared the alpha-amylase activity before and after the radiological examinations. The Mann-Whitney test was used to assess differences between males and females, and between patients with and without previous experience with radiographic examinations. All tests were performed using the software GraphPad Prism 7.04 (GraphPad Software, Inc; La Jolla, California, USA) at a significance level of $5 \%(a=0.05)$.

\section{Dentist perception on patient anxiety assessment}

Sample selection. Fifty dentists were invited to share their perception on their patients' anxiety levels related to dental imaging examinations used in their clinical

Table II. Absolute and relative frequency of potentially anxiogenic variables associated with radiographic imaging examinations.

\begin{tabular}{|c|c|c|}
\hline Questions & Yes & No \\
\hline \multicolumn{3}{|l|}{ My ANXIETY / FEAR... } \\
\hline 1. made me postpone the examination appointment & $1(2.1)$ & $46(97.9)$ \\
\hline 2. made me cancel or not attend the examination appointment & $1(2.1)$ & $46(97.9)$ \\
\hline 3. would make me (for females) postpone/cancel the examination if I was pregnant or & $37(78.7)$ & $10(21.3)$ \\
\hline
\end{tabular}

(for males) prevent my wife from taking the examination if she was pregnant.

ON THE DAY OF THE RADIOGRAPHIC EXAMINATION, I EXPERIENCED ANXIETY / FEAR...
4. in the waiting room
$9(19.2)$
$38(80.8)$
5. when called by the dentist to be radiographed
$9(19.2)$
$38(80.8)$
6 . inside the $\mathrm{X}$-ray examination room
8 (17.0)
$39(83.0)$
7. when was being positioned by the dentist to perform the X-ray
$26(55.3)$
$21(44.7)$
8. when the dentist left the room and I heard an alarm from the X-ray machine
8 (17.0)
$39(83.0)$
9. when I saw the radiographic image of my teeth on the computer monitor
$17(36.2)$
$30(63.2)$
10. when the dentist needed to repeat the radiographic examination
$6(12.7)$
$41(87.2)$
11. when the X-ray examination ended
$1(2.1)$
$46(97.9)$
12. while waiting for the radiographic report
$11(23.4)$
$36(76.6)$
13. as a consequence of pain when radiographs were being taken
14. from the $\mathrm{X}$-ray exposure
$8(17.0)$

DURING THE RADIOGRAPHIC EXAMINATION...

15. I felt my muscles tensed

$22(46.8)$

25 (53.2)

16. my breathing rate increased

7 (14.9)

$40(85.1)$

17. I sweat

2 (4.2)

45 (95.7)

18. I had nausea or stomachache

1 (2.1)

46 (97.9)

19. my heart rate increased

$21(44.7)$

$26(55.3)$ 
COSTA, E. D.; MARTINS, L. A. C.; CHAVES-JUNIOR, S. C.; SOUSA, E. T.; GAVIÃO, M. B. D.; POSSOBON, R. F. \& OLIVEIRA, M. L. Ansiedad de los pacientes relacionada con los exámenes radiográficos dentales: niveles, percepción y manejo. Int. J. Odontostomat., 15(4):971-979, 2021.

Table III. Characterization of the dentists included in this study.

\begin{tabular}{lrrrrr}
\hline Variables & & \multicolumn{2}{c}{ Dentists } \\
& & $\begin{array}{c}\text { Oral } \\
\text { Radiologists }\end{array}$ & $\begin{array}{c}\text { Dental } \\
\text { Practitioners }\end{array}$ & Pediatric Dentists & Total \\
\hline Sex [n (\%)] & Female & $11(57.9)$ & $13(76.5)$ & $10(71.4)$ & $34(68.0)$ \\
& Male & $8(42.1)$ & $4(23.5)$ & $4(28.6)$ & $16(32.0)$ \\
Age [years (SD)] & & $29.1(4.8)$ & $32.7(6.9)$ & $34.0(9.3)$ & $31.7(7.2)$ \\
Working experience [years (SD)\} & & $6.4(4.6)$ & $9.1(6.3)$ & $10.4(9.2)$ & $8.4(6.8)$ \\
\hline
\end{tabular}

SD - Standard deviation

routine by means of a qualitative-quantitative approach (Lefèvre \& Lefèvre, 2003; Costa et al., 2016, 2020).

For this assessment method, the sample size of 50 dentists was sufficient to reach saturation, which is when the answers no longer reveal new information (Vazquez et al., 2015). Most of the dentists were female (68\%), the mean age was of 32.1 years old (standard deviation of 7.6 years), and the pediatric dentists were the most experienced professionals working for an average of 10.4 years (standard deviation of 9.2 years) (Table III). All selected dentists had, at least, two years of clinical experience and were occasionally distributed in $19(38 \%)$ oral radiologists, 17 (34\%) general practitioners and $14(28 \%)$ pediatric dentists. In this study, the oral radiologists acquired extraoral radiographic images in adult patients whereas general and pediatric dentists acquired intraoral radiographic images in adults and children, respectively.

Dentist interview. The selected dentists were asked to answer the following two guiding questions: "How do you reassure patients with anxiety or fear of radiographic examinations?" and "How do you perceive the patients' anxiety?".

One researcher interviewed individually all dentists in a calm and quiet place using a voice recorder, and the answers were fully transcribed immediately after each interview to verify the saturation of responses (Costa et al., 2020; Vazquez et al.). When saturation was reached, the qualitative-quantitative analysis was initiated.

Qualitative-quantitative analysis. To assure that the data were verified from more than one perspective, two researchers individually selected the most significant aspects of the responses of each dentist (key expressions). Posteriorly, in consensus, the researchers confronted the key expressions obtained, which were synthesized in central ideas and grouped (Mialhe et al., 2011; Lefèvre \& Lefèvre; Costa et al.,
2016, 2020) (Table IV). This qualitative assessment generated the "discourse of the collective subject", a text in the first-person singular in which the perceptions and behaviors of the dentists were described as an individual discourse, respecting their colloquial language (Lefèvre \& Lefèvre; Costa et al., 2016, 2020). After, the frequency of participants who shared similar ideas (quantitative part) was calculated (Costa et al., 2016; Mialhe et al.). The Qualiquantisoft $囚$ software (SPI - Sales \& Pascoal Company, São Paulo, SP, Brazil) was used for this analysis.

\section{RESULTS}

Table $\mathrm{V}$ shows that, before the radiographic examination, the alpha-amylase activity was significantly lower for males $(p \leq 0.05)$ than for females, who had the same level of alpha-amylase activity after the exam ( $p>0.05)$. For men, the alpha-amylase activity increased after the exam $(p \leq 0.05)$, presenting similar alpha-amylase activity as women $(p>0.05)$. Patients with no previous experience with radiographic exams presented a significant increase of the alpha-amylase activity after the exam $(p \leq 0.05)$, and no significant difference was observed between the assessment times (before and after the radiographic exam) for patients with previous experience $(p>0.05)$. When compared to panoramic radiography, СВCT led to a significant increase of the alpha-amylase activity after the exam $(p \leq 0.05)$, and there were no significant differences before and after the exam for patients who underwent panoramic radiography $(p>0.05)$.

Most of the patients reported that anxiety/fear would make them postpone or cancel the radiographic exam appointment in case of pregnancy $(78.7 \%)$, and that they experienced anxiety when they were being positioned in the machine $(55.3 \%)$. Regarding the physiological responses of anxiety, most of the answers were positive for muscle tension ( $46.8 \%$ of patients), 


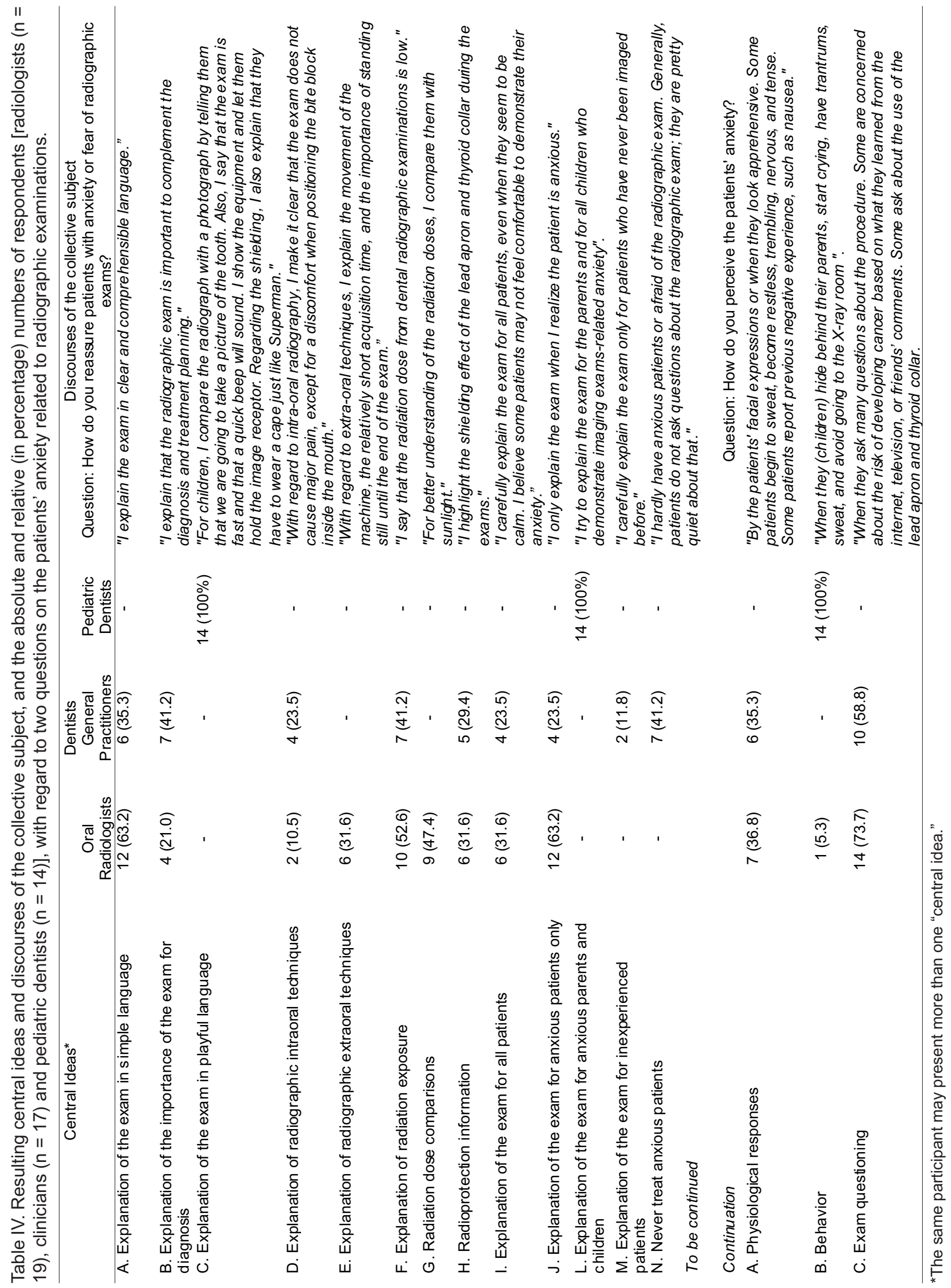


followed by an increase in the heart rate $(44.7 \%$ of the patients) (Table II).

The assessment of the dentists' perception on their patients' anxiety resulted in the discourse of the collective subject (Table IV) and the identification of the following central ideas:

\section{- Strategies to reassure patients with anxiety or fear of radiographic examinations:}

Oral radiologists and General practitioners Explanation of the examination in simple language; explanation of the importance of the examinations for the diagnosis; explanation of the radiation exposure; radiation dose comparisons; explanation of the exam for anxious patients only.

Oral Radiologists - Further explanation on radiation dose comparisons.

General Practitioners - Never treated anxious patients.

Pediatric Dentists - Explanation of the exam in playful language; explanation of the exam for anxious parents and children.

\section{- Perception the patients' anxiety:}

Oral Radiologists and General Practitioners Physiological responses; exam questioning.

\section{Pediatric Dentists - Behavior.}

To reassure patients about the radiographic exam, oral radiologists reported that they explain the full examination in simple language, tell the patients that the radiation dose of the dental radiographic exams is low, and make it more understandable by comparing the radiation dose with sunlight. However, oral radiologists reported that they only provide such explanations when the patient demonstrates anxiety, which is perceived when they ask questions about the exams, mostly about the radiation-related risks and protection (Table IV).

General practitioners reported that they explain the importance of the radiographic exams in the diagnostic process, and also the relatively low radiation dose. However, they consider that patients have no fear or anxiety with the radiographic examinations and, similarly to oral radiologists, general practitioners perceive anxiety from the patients' reports (Table IV). All pediatric dentists reported that they use playful language to reassure children about the radiographic examination, and that anxiety is perceived by their behavior (Table IV).

\section{DISCUSSION}

The present study investigated patients' anxiety levels related to dental radiographic examinations and dentists' perception and management. Specialists in oral radiology, general practitioners, and pediatric dentists who acquire radiographic images in their clinical routine participated of this study. In addition,

Table V. Medians and interquartile ranges of alpha-amylase activity $(\mathrm{U} / \mathrm{mL})$ before and after the radiologic examination as a function of the sex, previous experience with the examination and the imaging modality.

\begin{tabular}{|c|c|c|c|c|}
\hline Variables & & Before & After & $p$-value \\
\hline \multirow[t]{3}{*}{ Sex } & Female & $25.51(19.85)$ & $28.59(17.60)$ & 0.074 \\
\hline & Male & $14.01(8.60)$ & $27.98(14.60)$ & $0.028^{*}$ \\
\hline & $p$-value & $0.021^{*}$ & 0.619 & \\
\hline \multirow[t]{3}{*}{ Previous experience } & Yes & $25.51(18.64)$ & $27.19(9.66)$ & 0.375 \\
\hline & No & $19.12(15.67)$ & $34.01(28.73)$ & $0.004^{*}$ \\
\hline & p-value & 0.361 & 0.315 & \\
\hline \multirow[t]{4}{*}{ Imaging modality } & Panoramic & $19.58(14.28)$ & $25.56(11.34)$ & 0.199 \\
\hline & radiography & & & \\
\hline & CBCT & $26.22(27.40)$ & $32.05(28.23)$ & $0.050^{*}$ \\
\hline & p-value & 0.259 & 0.070 & \\
\hline
\end{tabular}

*Statistically significant $(p \leq 0.05)$. The $p$-values in the last colum are for comparisons between before and after the radiologic examination (Wilcoxon test). The p-values in the bottom of each group of variables are for comparisons between independent variables (Mann-Whitney test). 
COSTA, E. D.; MARTINS, L. A. C.; CHAVES-JUNIOR, S. C.; SOUSA, E. T.; GAVIÃO, M. B. D.; POSSOBON, R. F. \& OLIVEIRA, M. L. Ansiedad de los pacientes relacionada con los exámenes radiográficos dentales: niveles, percepción y manejo. Int. J. Odontostomat., 15(4):971-979, 2021.

pediatric dentists also participated, due to the specific anxiety of children with the dental environment (Karibe et al.; Salas Huamani et al.).

The results showed that, for most of the oral radiologists $(73.7 \%)$ and general practitioners $(58.8$ $\%$ ), anxiety is perceived only when their patients report it. However, it is important to consider that patients not always verbalize that they are anxious possibly because they feel embarrassed, unlike children who easily demonstrate anxiety through disruptive behaviors, which can be easily detected. Thus, to avoid bias related to the patients' reports, anxiety was assessed through a biological marker, which showed significant differences in alphaamylase activity before and after the radiographic exam, and is indicative of anxiety (Karibe et al.; Furlan et al.; Salas Huamani et al.).

In relation to sex, alpha-amylase activity was significantly higher before the radiographic exam for women, whereas for men, the activity was significantly higher after the exam. According to the literature, women present more dental anxiety than men (Astramskaite' et al.; Yıldırım et al.; Ihara et al., 2018), and this reaction can be explained due to the related cerebral differences, which are responsible for increased anxiety or phobias among women (Astramskaite et al.; Yıldırım et al.). According to Wabnegger et al. (2014), women has higher percentage of grey matter in comparison to men, which might influence behaviors such as dental anxiety. The most frequently reported physiological response to anxiety was muscle tension $(46.8 \%)$ followed by an increase in heart rate $(44.7 \%)$, probably due to the positioning in the device (55.3 $\%)$ and the expectation of the exam end.

Patients who underwent magnetic resonance imaging (Eshed et al., 2007) and multi-slice computed tomography (Heyer et al., 2015) experienced more considerable discomfort when the exam was performed in the head and neck region than in other regions of the body due to claustrophobia generated when entering the gantry. In oral radiology, extraoral devices present varying physical configurations and tend to be less intimidating for the patients. Even though, patients may not have a total perception of the device operation, and anxiety may be generated due to a lack of control over the procedure. In the present study, although the positioning of the patients was similar for panoramic radiography and $\mathrm{CBCT}$, the alpha-amylase activity was significantly higher after the CBCT, which may be related to the slightly longer acquisition time in $\mathrm{CBCT}$, and consequent increase of anxiety.

From a clinical perspective, a greater difficulty and increased time for patient positioning is observed in women before the radiographic exam. For men, the increased anxiety level after the exam may be related to insecurity, impatience, and discomfort due to the positioning in the device, which may lead to greater resistance of undergoing to radiographic exams in the future.

A previous study (Chapman et al., 2010) revealed that anxiety levels were higher in patients undergoing magnetic resonance imaging who had never been in contact with this imaging modality before, and lower in a second session. This was also confirmed in the present study since patients with no previous experience had a significantly higher alpha-amylase activity after the test probably because they were not familiar with the operation of the machine. This highlights the importance of a complete explanation to patients on the image acquisition process. Previous studies have found that patients have limited knowledge regarding medical imaging exams such as multi-slice computed tomography (Heyer et al.) and magnetic resonance imaging. 26 The lack of clear professional-patient communication (Heyer et al.) can lead to patient insecurity and be an additional factor in increasing anxiety level (Munn \& Jordan, 2011; Heyer et al.; Tugwell-Allsup \& Pritchard, 2018). Thus, a detailed explanation to patients on the image acquisition process and radiation protection is extremely important.

To reassure patients about imaging examinations-related anxiety, most oral radiologists reported that they provide explanations in accessible language about the procedures required during the examination. Similarly, the pediatric dentists reported that make use of playful language. Among the general practitioners, the most common approach was to emphasize the importance of the radiographic examination to complement the clinical diagnosis. The concern for the findings or diagnosis has also been considered as an anxiogenic factor in medical imaging (Heyer et al.; Chapman et al.; Munn \& Jordan; TugwellAllsup \& Pritchard). However, most of the examinations used in this study had as a clinical task the overall evaluation of the oral cavity, which may have been the cause of few patients showing lower anxiety levels related to the visualization of the image and the imaging report. 
In the present study, few patients reported anxiety related to the ionizing radiation associated risks, which may suggest limited knowledge on this topic. Similar results were found in studies with patients undergoing multi-slice computed tomography examinations (Ludwig \& Turner, 2002; Baumann et al., 2011). Another interesting finding of the present study regarding exposure to radiation was the fact that pediatric dentists did not report whether their patients' parents expressed anxiety when radiographic examinations were indicated for their kids. Chiri et al. (2013) found that, although the parents had a good perception of the diagnostic value of X-rays, most of them were unaware of the exposure risks and the increased radiosensitivity of children.

Regarding explaining the patients about the radiation dose employed in dental examinations, a considerable number of oral radiologists was concerned to compare the radiation dose of the examinations with sunlight. According to Ludwig \& Turner, this approach is beneficial because patients understand well the harmful effects of solar radiation even having limited knowledge about the radiation dose of the imaging examinations. General practitioners reported informing their patients that radiation dose is low in oral radiographic examinations, although they believe that patients are not anxious about it. Another interesting finding was that most patients revealed overestimated precaution by stating that the radiographic examination should be avoided in case of pregnancy, which opposes their underestimation of personal risks. It is suggested that such a reaction is probably due to common sense media or the warning board hanging on the wall.

Dentists should take into consideration individual previous experience of patients and how familiar they are with the examination and radiation protection concepts. Also, professionals and dentistry students should instruct patients in a language of easy understanding for a better comprehension of the procedures. Future studies should be performed to evaluate strategies to maximally reduce the anxiety of patients and its manifestations in the radiology clinic, reducing the need for retakes.

\section{CONCLUSION}

Dental radiographic examinations may be a source of anxiety with salivary alpha-amylase levels depending on the patient's gender and experience, imaging modality, and moment in relation to the image acquisition. Dentists perceive anxiety in adult and pediatric patients differently.

\section{ACKNOWLEDGMENTS}

The authors thank the Coordination for the Improvement of Higher Education Personnel (CAPES) - Finance Code 001.

COSTA, E. D.; MARTINS, L. A. C.; CHAVES-JUNIOR, S. C.; SOUSA, E. T.; GAVIÃO, M. B. D.; POSSOBON, R. F. \& OLIVEIRA, M. L. Ansiedad de los pacientes relacionada con los exámenes radiográficos dentales: niveles, percepción y manejo. Int. J. Odontostomat., 15(4):971-979, 2021.

RESUMEN: Este estudio evaluó los niveles de ansiedad en los pacientes relacionados con exámenes radiográficos dentales, además de la percepción y el manejo de los dentistas. Se midió la actividad de la alfa-amilasa salival (sAA) de 47 pacientes antes y después de la exposición a exámenes radiográficos para evaluar su nivel de ansiedad y se comparó mediante la prueba de Wilcoxon. La prueba de Mann-Whitney evaluó la actividad de la sAA relacionada con el sexo, el tipo de examen y la experiencia previa con exámenes radiográficos. Se entrevistó a 50 dentistas utilizando un guión semiestructurado de preguntas abiertas sobre la percepción de la ansiedad de sus pacientes. Antes del examen radiográfico, la actividad de la $\mathrm{SAA}$ era significativamente mayor para las mujeres $(p \leq 0.05)$. La actividad de SAA aumentó significativamente después del examen para los hombres, pacientes de ambos sexos sin experiencia previa y para los que se sometieron a CBCT $(p \leq 0.05)$. Se informó que se observa ansiedad en el habla de los pacientes adultos y en el comportamiento de los pacientes pediátricos. Los exámenes radiográficos dentales pueden ser una fuente de ansiedad para las mujeres antes del examen. Tras la exploración, los hombres, los pacientes sin experiencia previa y los sometidos a CBCT presentan niveles de ansiedad más elevados. Los dentistas perciben la ansiedad en los pacientes adultos y pacientes pediátricos de manera diferente.

PALABRAS CLAVE: ansiedad, alfa-amilasas, radiología, odontología, atención al paciente.

\section{REFERENCES}

Astramskaite, I.; Poskevicius, L. \& Juodzbalys, G. Factors determining tooth extraction anxiety and fear in adult dental patients: a systematic review. Int. J. Oral Maxillofac. Surg., 45(12):1630-43, 2016.

Baumann, B. M.; Chen, E. H.; Mills, A. M.; Glaspey, L.; Thompson, N. M.; Jones, M. K. \& Farner, M. C. Patient perceptions of computed tomographic imaging and their understanding of radiation risk and exposure. Ann. Emerg. Med., 58(1):1-7, 2011. 
Bradford, M. M. A rapid and sensitive method for the quantitation of microgram quantities of protein utilizing the principle of proteindye binding. Anal. Biochem., 72:248-54, 1976.

Chapman, H. A.; Bernier, D. \& Rusak, B. MRI-related anxiety levels change within and between repeated scanning sessions. Psychiatry Res., 182(2):160-4, 2010.

Chiri, R.; Awan, S.; Archibald, S. \& Abbott, P. V. Parental knowledge and attitudes towards dental radiography for children. Aust. Dent. J., 58(2):163-9, 2013.

Costa, E. D.; Martins, L. A. C.; Cral, W. G.; Peroni, L. V.; Freitas, D. Q. \& Oliveira, M. L. Assessment of dentists' behaviour on the use of patients' images. Eur. J. Dent. Educ., 24(3):513-7, 2020.

Costa, E.D.; Ambrosano, G. M. B. \& Pinelli, C. Behavior and perceptions of hand hygiene practices among dental students. R. G. O. Rev. Gaúch. Odontol., 64(4):434-41, 2016.

Doebling, S. \& Rowe, M. M. Negative perceptions of dental stimuli and their effects on dental fear. J. Dent. Hyg., 74(2):110-6, 2000.

Eshed, I.; Althoff, C. E.; Hamm, B. \& Hermann, K. G. Claustrophobia and premature termination of magnetic resonance imaging exams. J. Magn. Reson. Imaging, 26(2):401-4, 2007.

Furlan, N. F.; Gavião, M. B.; Barbosa, T. S, Nicolau, J. \& Castelo, P. M. Salivary cortisol, alpha-amylase, and heart rate variation in response to dental treatment in children. J. Clin. Pediatr. Dent., 37(1):83-7, 2012.

Heyer, C. M.; Thüring, J.; Lemburg, S.P.; Kreddig, N.; Hasenbring, M.; Dohna, M. \& Nicolas, V. Anxiety of patients undergoing CT imaging - an underestimated problem? Acad. Radiol., 22(1):10512, 2015.

Ihara, Y.; Fukuda, K. I.; Saita, N. \& Ichinohe, T. Male gender and high trait anxiety are two major factors associated with severe dental fear and avoidance. Anesth. Prog., 65(3):177-80, 2018.

Karibe, H.; Aoyagi-Naka, K. \& Koda, A. Maternal anxiety and child fear during dental procedures: a preliminary study. J. Dent. Child. (Chic.), 81(2):72-7, 2014.

Lefèvre, F. \& Lefèvre, A. M. C. O discurso do sujeito coletivo: um novo enfoque em pesquisa qualitativa (Desdobramentos). Caxias do Sul, Educs, 2003.

Ludwig, R. L. \& Turner, L. W. Effective patient education in medical imaging: public perceptions of radiation exposure. J. Allied Health, 31(3):159-64, 2002.

Mialhe, F. L.; Lefèvre, F. \& Lefèvre, A. M. Community health agents and their educational practices in oral health: a qualitative/ quantitative evaluation. Cien. Saude Colet., 16(11):4425-32, 2011.

Munn, Z. \& Jordan, Z. The patient experience of high technology medical imaging: A systematic review of the qualitative evidence. JBI Libr. Syst. Rev., 9(19):631-78, 2011.

Oosterink, F. M.; de Jongh, A. \& Aartman, I. H. What are people afraid of during dental treatment? Anxiety-provoking capacity of 67 stimuli characteristic of the dental setting. Eur. J. Oral Sci., 116(1):44-51, 2008.

Rohleder, N. \& Nater, U. M. Determinants of salivary a-amylase in humans and methodological considerations. Psychoneuroendocrinology, 34(4):469-85, 2009.

Said, H.; Finkelman, M. \& Rosenberg, M. Salivary cortisol, salivary alpha amylase, and the dental anxiety scale. Anesth. Prog., 60(2):46-53, 2013.

Salas Huamani, J. R.; Barbosa, T. S.; de Freitas, C. N.; de Sousa, K. G.; Gavião, M. B. D.; Leal, S. C.; Mialhe, F. L. \& Castelo, P. M. Assessment of anxiety and stress markers in children submitted to educational strategies and ART-restoration: a randomized clinical trial. Arch. Oral Biol., 97:191-7, 2019.

Spin-Neto, R. \& Wenzel, A. Patient movement and motion artefacts in cone beam computed tomography of the dentomaxillofacial region: a systematic literature review. Oral Surg. Oral Med. Oral Pathol. Oral Radiol., 121(4):425-33, 2016.
Tugwell-Allsup, J. \& Pritchard, A. W. The experience of patients participating in a small randomized control trial that explored two different interventions to reduce anxiety prior to an MRI scan. Radiography (Lond.), 24(2):130-6, 2018.

Vazquez, F. de L.; Cortelazzi, K. L.; Gonçalo, C. da S.; Bulgareli, J. V.; Guerra, L. M.; Tagliaferro, E. S.; Mialhe, F. L. \& Pereira, A. C. Qualitative study on adolescents' reasons to non-adherence to dental treatment. Cien. Saude Colet., 20(7):2147-56, 2015.

Wabnegger, A.; Scharmüller, W. \& Schienle, A. Sex-specific associations between grey matter volume and phobicsymptoms in dental phobia. Neurosci. Lett., 580:83-7, 2014.

Yıldırım, S.; Bakkal, M.; Bulut, H. \& Selek, S. Quantitative evaluation of dental anxiety indicators in the serum and saliva samples of children treated under general anesthesia. Clin. Oral Investig., 22(6):2373-80, 2018.

Yıldızer Keris, E. Effect of patient anxiety on image motion artefacts in CBCT. BMC Oral Health, 17(1):73, 2017.

Corresponding author:

Eliana Dantas Costa

Division of Oral Radiology

Department of Oral Diagnosis

Piracicaba Dental School

University of Campinas

Av. Limeira 901

Areião, Piracicaba

SP. Zip Code 13414-018

BRAZIL

E-mail: edantasc@yahoo.com.br 